
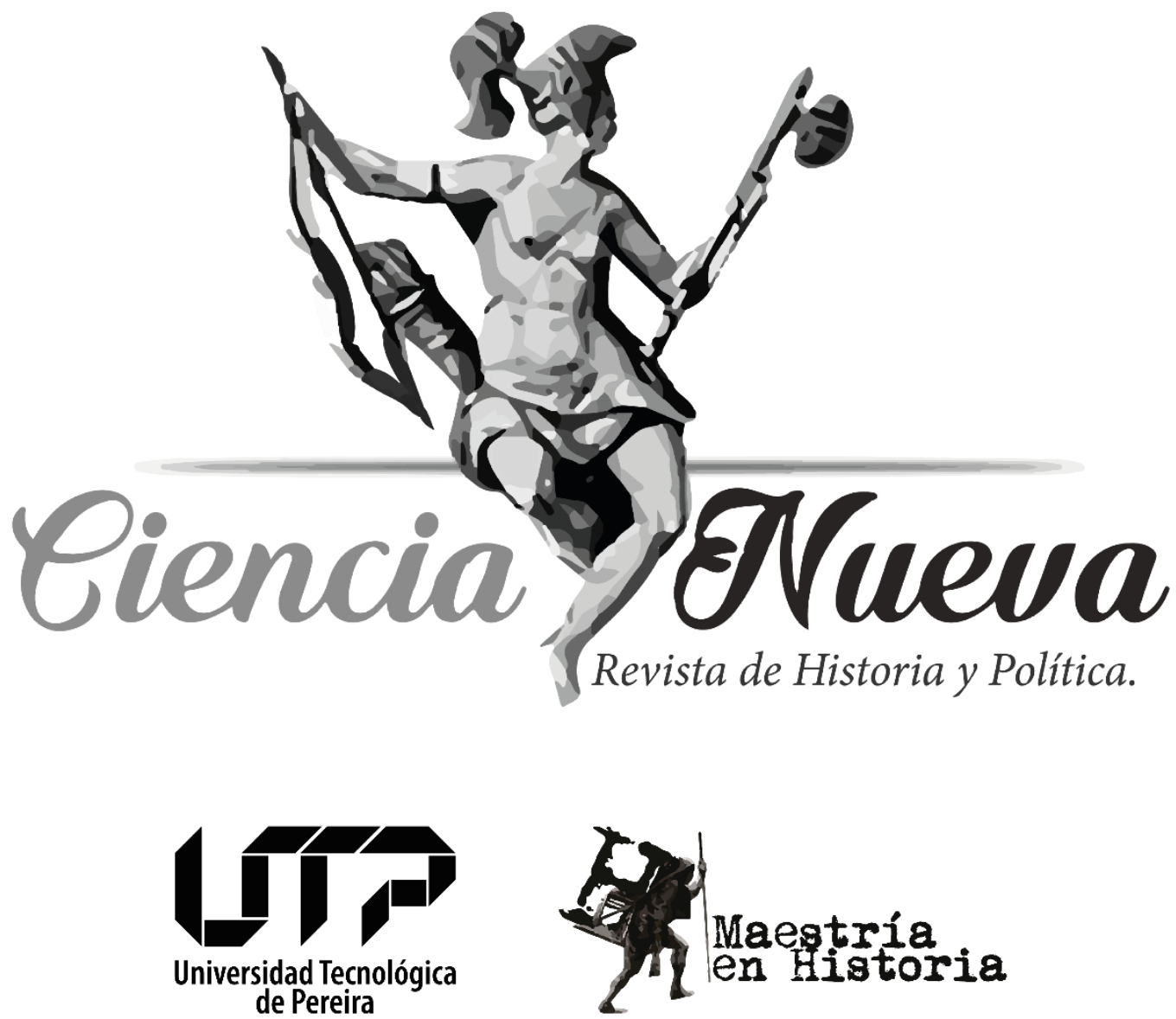

ESTUDIOS HISTÓRICOS

MIRAR EL MAR DESDE LAS ESPUMAS: UNA MIRADA AL INTERCAMBIO CULTURAL ENTRE MÉXICO Y COLOMBIA DURANTE LOS AÑOS CUARENTA LOOKING AT THE SEA FROM THE FOAMS: A LOOK AT THE CULTURAL EXCHANGE BETWEEN MEXICO AND COLOMBIA DURING THE 1940S Yezid David Sequeda Garrido pp. 47-67

Vol. 4 Núm. 1 | Enero-Junio de 2020 Pereira, Colombia 
Yezid David Sequeda Garrido

\title{
MIRAR EL MAR DESDE LAS ESPUMAS: UNA MIRADA AL INTERCAMBIO CULTURAL ENTRE MÉXICO Y COLOMBIA DURANTE LOS AÑOS CUARENTA*
}

\section{LOOKING AT THE SEA FROM THE FOAMS: A LOOK AT THE CULTURAL EXCHANGE BETWEEN MEXICO AND COLOMBIA DURING THE 1940S}

\author{
Yezid David Sequeda Garrido** \\ yezu123@gmail.com
}

ORCID: http://orcid.org/0000-0002-4715-5734

$\begin{array}{cl}\text { Recibido: } & 07 \text { de enero de } 2020 . \\ \text { Revisado: } & 21 \text { de febrero de } 2020 . \\ \text { Aceptado: } & 23 \text { de marzo de } 2020 . \\ \text { Publicado: } & 04 \text { de septiembre de } 2020 .\end{array}$

\section{Resumen}

Este artículo busca dar cuenta de importantes matices de los vínculos extradiplomáticos colombo mexicanos, visibles en el continuo cruce de información ligado con el ámbito de la cultura, la educación y la diplomacia durante un amplio trayecto de la primera mitad del siglo XX.

La idea es acercarse al influjo que ejercieron las políticas culturales del Gobierno mexicano, en un periodo en el que la propaganda y la difusión de un proyecto que apeló a la cultura y a las manifestaciones artísticas de las mayorías hizo presencia en el entorno de la relación de ambos países. Lo que sirvió de modo directo a propósitos de cohesión colectiva en los que expresiones artísticas, manifestaciones folclóricas y diversas tradiciones provenientes del campo mexicano encontraron, en este proyecto dirigido, un espacio para su difusión y su apropiación, como formas vinculantes y enlaces válidos para dar cuenta de la identidad nacional.

Palabras clave: historia, diplomacia, cultura, relaciones exteriores, México, Colombia, intercambio.

\begin{abstract}
The article seeks to give an account of important shades of the extra-diplomatic links visible between Mexico and Colombia in the continuous crossover of information linked to the field of culture, education, and diplomacy during a wide period of the first half of the 20th century. The idea is to approach the influence that the Mexican government's cultural policies exerted, in a period in which the propaganda and the diffusion of a project that appealed to the culture and the artistic manifestations of the majority, made a presence in the environment of the relation of both countries, while it served in a direct way to purposes of collective cohesion in which artistic expressions, folkloric manifestations, and diverse traditions coming from the Mexican field, found in this directed project, a space for its diffusion and its appropriation, as binding forms and as valid links to give an account of the national identity.
\end{abstract}

Key Words: history, diplomacy, culture, external relationships, Mexico, Colombia; Exchange.

\footnotetext{
* Este documento respeta las directrices y normas dispuestas en la Declaración de Ética de Publicación de Ciencia Nueva, Revista de Historia y Política. Esta declaración puede consultarse en la página web de la revista: http://revistas.utp.edu.co/index.php/historia

${ }^{* *}$ Historiador de la Universidad Industrial de Santander, magíster en Historia Política y doctor en Historia por el Centro de Investigaciones y Estudios Superiores en Antropología Social, CIESAS-Unidad Peninsular.
} 
...Las relaciones entre Colombia y México son sumamente cordiales y no siendo posible por ahora intensificarlas, por medio del intercambio comercial debido a las dificultades de comunicación, hay que buscar los medios culturales. Un mutuo conocimiento de nuestra respectiva pintura, escultura, poesía, literatura, música y sobre todo de nuestra ideología, con el objeto de ser más tolerantes en la apreciación de nuestros problemas y de los sistemas y métodos que cada cual adopte para resolverlos... Julio Madero $^{129}$.

\section{Introducción}

$\mathrm{M}$ éxico vivió en la primera mitad del siglo XX un proceso de modernización de su infraestructura, un crecimiento urbano y la consolidación de sus aparatos políticos, como muchos países latinoamericanos. Una de las trasformaciones visibles de este periodo estuvo asociada con la reconfiguración del sistema político mexicano, en un proceso que fue posible gracias a la consolidación del poder presidencial y a la búsqueda de reformas sociales, sobre todo durante el gobierno del general Lázaro Cárdenas. Durante este periodo, el nacionalismo sirvió a su gobierno como una ideología generadora de cohesión social, en medio de la apertura de espacios y de escenarios de institucionalización ${ }^{130}$. Para autores como Luis Gonzales, el México indio, el México ranchero y el México urbano, configuraron el torbellino que fue el sexenio cardenista y en el que cada uno de estos mundos — con variados niveles de influencia - jugó un papel activo o pasivo en la vida nacional ${ }^{131}$.

Las asociaciones obreras y campesinas contribuyeron a la integración de un partido institucional, y el ascenso de una dirigencia política supo sacar provecho de las distintas formas de sociabilidad, a través de su inserción en el aparato estatal. Para Javier Mac Gregor, esta inserción de nuevos actores sociales en el escenario político mexicano impulsó la creación de un partido oficial, que sirvió al proyecto de reformas que se había trazado el gobierno cardenista, mientras el Partido de la Revolución mexicana sirvió como catalizador de la acción política popular y definió un proceso de transición hacia una nueva etapa en la política nacional ${ }^{132}$. Durante los años treinta, el Estado, como generador de consenso entre los ciudadanos, protagonizó la articulación de extensas redes clientelares que se encaminaron en la consolidación de un proyecto político pensado y planeado a largo plazo. El liderazgo de Lázaro Cárdenas permitió articular los intereses de una clase dirigente surgida de la revolución con los de una amplia masa campesina a la que Cárdenas supo conocer ${ }^{133}$. Sin embargo, las reformas emprendidas y el empoderamiento dado a sectores obreros y campesinos generaron un fuerte impacto sobre la organización económica del país, lo que golpeó poderosos intereses y generó divisiones políticas en el seno de la sociedad mexicana $^{134}$. El proyecto programático del general Cárdenas fue un eje clave para el surgimiento de una nueva etapa en la Revolución mexicana a la que se incorporaron personajes como Vicente Lombardo Toledano, quien tuvo un gran protagonismo en el espectro de la política mexicana de los años treinta y cuarenta, y quien también tuvo particular

\footnotetext{
${ }^{129}$ El Tiempo, 1 de enero de 1929.

${ }^{130}$ Bertha Lerner y Susana Ralsky, El poder de los presidentes. Alcances y perspectivas. 1910-1973 (México, IMEP, 1976), 101.

${ }^{131}$ Luis González, Los artífices del cardenismo (México: El Colegio de México, 1979), 45.

132 Javier Mac Gregor, "El nuevo presidencialismo, corporaciones y partidos políticos", en El cardenismo, 19321940, coord. por Samuel León y Gonzales (México: FCE, 2011), 326.

133 Adolfo Guilly, El cardenismo. Una utopía mexicana (México: Ediciones Era, 1994), 156.

${ }^{134}$ Luis Medina, Historia de la Revolución Mexicana. Del cardenismo al avilacamachismo. Tomo 18 (México: El Colegio de México, 1978), 13.
} 
influencia en las iniciativas de organización internacional obrera y campesina de distintos países latinoamericanos ${ }^{135}$. En un momento en que la política petrolera del cardenismo buscaba apoyos externos, y la búsqueda de alianzas entre sectores obreros mostraba signos de cercanía con el Gobierno mexicano, su presencia, su liderazgo y sus cualidades políticas resultaron relevantes en este proceso de proyección internacional.

Hacia el mes de septiembre de 1942, el líder sindical Vicente Lombardo Toledano, junto a su esposa Rosa María Otero y Guillermo Rodríguez, tuvieron la oportunidad de visitar las ciudades de Barranquilla y Bogotá, en medio de invitaciones a eventos organizados por líderes sindicales colombianos adscritos a las distintas centrales y asociaciones de obreros y trabajadores del país. Esta visita del líder sindical mexicano a Colombia era vista por las organizaciones obreras como un grato acontecimiento y como una oportunidad para acercarse a una figura a la que admiraban por su lucha y defensa de la clase obrera ${ }^{136}$. Igualmente, la figura de Lombardo Toledano apareció asociada con las ideas de unidad y de cohesión del movimiento obrero mexicano ${ }^{137}$.

Mientras en México el cardenismo emprendía un proceso de apertura política y de alianzas estratégicas con sectores obreros, campesinos y cercanos a la izquierda, en Colombia el presidente Alfonso López Pumarejo realizaba hacia 1936 un proceso similar con sectores sindicales, socialistas y comunistas, en un escenario que vino a dinamizar el entorno político colombiano. Tanto en México como en Colombia, esta vinculación de trabajadores, campesinos e intelectuales a las estructuras de los partidos, así como también el diálogo sindical y la participación en el andamiaje institucional ofrecido por los dos Gobiernos, fueron factores que sirvieron a este proyecto vinculante. Durante el tiempo en que el entorno internacional vivía la emergencia de proyectos políticos cercanos con el republicanismo, el socialismo y los "modernismos reaccionarios", la política latinoamericana se veía influida por los ecos de estas ideas entre adhesiones y alianzas en contrario, gestadas a distintos niveles en países como México y Colombia ${ }^{138}$. En un contexto mediado por el ascenso de los fascismos y por el auge de retoricas que miraban con recelo el avance comunista, el liberalismo, la democracia y su legado en el mundo occidental, los discursos políticos adquirieron un matiz acorde con este momento histórico que los convirtió en inspiración para políticos conservadores, tanto en México como en Colombia durante los años treinta.

Este mismo periodo marcó en Colombia el inicio de la hegemonía del Partido Liberal, con la llegada a la presidencia de Enrique Olaya Herrera, después de un largo periodo de control político por parte del partido conservador iniciado en 1886, en el que acontecimientos como la guerra de los Mil Días, la separación de Panamá y el conflicto de las bananeras, fueron hechos de gran incidencia en la vida política nacional. Para este momento, los desacuerdos políticos y las divisiones internas propias del conservatismo colombiano

${ }^{135}$ Rosendo Bolívar, "El lombardismo y la Confederación de Trabajadores de América Latina", Revista Mexicana de Ciencias Políticas y Sociales 41, n. ${ }^{\circ} 163$ (1996): 191-192.

${ }^{136}$ El Tiempo, 21 y 25 de septiembre de 1942, 1 y 15.

${ }^{137}$ Daniela Spenser, "La cimentación de la Confederación de Trabajadores de México", Tzintzun. Revista de Estudios Históricos, n. ${ }^{\circ}$ 60, julio-diciembre (2014): 256.

138 De acuerdo con Javier Guerrero y siguiendo los postulados de Jeffrey Herft, los "modernismos reaccionarios" fueron proyectos políticos, a su manera, revolucionarios nacionalistas que se caracterizaron por el rechazo a la modernidad democrática o liberal, representada en la Revolución francesa y a una "proclamada modernidad socialista", representada en la Revolución de Octubre, al igual que a las realidades derivadas de la Revolución Industrial y a los avances científicos, pero, de manera contradictoria, con fe ciega en la técnica. Para un mayor detalle véase Javier Guerrero, El proceso político de las derechas en Colombia y los imaginarios sobre las guerras internacionales. 1930-1945 (Tunja: UPTC, 2014), 46-48. 
contribuyeron a que perdiera en las elecciones de 1930 el control político y rezagara sus campos de dominio en los cuerpos colegiados.

Esta ruptura con el poderío conservador, iniciada por Olaya Herrera, definió de un modo distintivo los rasgos de un periodo que en la historia nacional es conocido como la República Liberal, inmerso en un relevo generacional que dio cabida a nuevos actores, a nuevas formas de hacer política y a nuevos espacios de sociabilidad. De acuerdo con Herbert Braunw, a esta generación de políticos que gobernaron Colombia, tiempo después de terminada la guerra de los Mil Días, es preciso definirla como una generación de "convivialistas", categoría que sirve para representar a quienes ejercieron el poder nacional desde alguno de los partidos tradicionales, en un periodo de relativa paz, que estuvo acompañado por una expansión económica iniciada a partir de los años veinte. Este periodo configuró una serie de alianzas, consensos y equilibrios entre las élites políticas y económicas colombianas, que hizo posible la apertura del mercado interno, el aumento de las exportaciones, el crecimiento económico y un cambio en los modos de hacer y de ejercer la política. Este periodo que va de los años veinte a la década del cuarenta, además de representar un relevo generacional, implicó la ruptura con una tradición caudillista heredada del siglo XIX, en donde la milicia y la política, configuraban un escenario que dotaba de autoridad y legitimidad a los líderes y actores del liberalismo y el conservatismo colombiano $^{139}$.

\section{La promoción cultural en México y Colombia}

La intervención pública en el ámbito de la cultura estuvo mediada en México y Colombia, durante los años treinta y cuarenta del siglo XX, por una política encaminada a reconocer valores y expresiones populares. Pensar la política cultural como una "acción dirigida", que influía sobre la sociedad a partir de la intervención estatal en las artes, en la educación y en el fomento del folclor, fue un factor que dinamizó patrocinios, mecenazgos, formas de difusión y políticas públicas, que oxigenaron la relación de algunos artistas e intelectuales con el aparato estatal. Al hacerlos partícipes de una intención canalizada y administrada por las vías gubernativas, la política cultural de los años treinta y cuarenta en México y Colombia logró realzar expresiones de una cultura dirigida, a veces opuesta a la cultura vivida y a la producción de sentidos y de manifestaciones propias de su andamiaje múltiple y cotidiano ${ }^{140}$.

Expresiones como el muralismo mexicano, junto al realce del folclor nacional y la política cultural promovida por los gobiernos posrevolucionarios, lograron influir en la Republica Liberal de la mano de las ideas pregonadas por Olaya Herrera, por la Revolución

\footnotetext{
${ }^{139}$ Herbert Braunw, Mataron a Gaitán. Vida pública y violencia urbana en Colombia (Editorial Aguilar, 1985), 23-28.

${ }^{140}$ De acuerdo con Philippe Urfalino el estudio de estas formas de intervención pública sobre la cultura, las artes y la educación resultan de gran utilidad para comprender el conjunto de representaciones producidas y consumidas por un grupo social en un determinado momento. Para el autor, la historia de la política cultural y el análisis de la evolución de los sistemas de asignación de recursos y de estatutos para los artistas (mecenazgos, corporaciones, academias, mercados, el Estado providencial) permite situar el surgimiento, las modalidades y los impactos de la intervención de los Estados y otras instancias públicas modernas. Para un mayor detalle véase Philippe Urfalino, "La historia de la política cultural", en Para una historia cultural, Jean-Pierre Rioux y Jean François Sirinelli (México: Editorial Taurus, 1997), 330. También es posible encontrar alusiones a la política cultural y sus alcances en América Latina en Néstor García, ed., "Políticas culturales y crisis de desarrollo: un balance latinoamericano”, en Políticas Culturales en América Latina (México: Editorial Grijalbo, 1987), 1361.
} 
en Marcha de López y por los sucesivos mandatos liberales que gobernaron Colombia hasta 1946, año del retorno conservador al mando presidencial. La cultura no fue entendida como un escenario de producción continua de símbolos, significados y representaciones, sino como un campo de acción que permitía dar continuidad a lo nacional y albergar en el Estado una amplia gama de expresiones, identidades y espacios vinculantes. En esta noción de la cultura, el Estado aparece como el lugar en que se condensan los valores nacionales, se otorga un orden a las partes de una sociedad, mientras se regulan sus conflictos y se le hace partícipe de una estructura mayor de cohesión ${ }^{141}$.

Durante años la cultura de la Revolución mexicana se fundió con otras agendas políticas y culturales, en tanto que las visiones de los muralistas, las nuevas actitudes hacia los indígenas y el interés de los latinoamericanos por la región fueron influyentes en el extranjero $^{142}$. El muralismo ${ }^{143}$ mexicano fue durante los años treinta y cuarenta un referente inmediato en Colombia, en busca de una pedagogía pública y en medio de intentos por acercar el arte a la ciudadanía, generar identidad y cohesión social. Fue también un motivo inspirador para querer emular — con muy poco éxito - esta experiencia pictórica en espacios públicos nacionales y afianzar esta técnica, cultivada por algunos pintores bogotanos y antioqueños. Su expresividad y su alto contenido político fueron un ejemplo a seguir para los ejercicios artísticos que artistas como Ignacio Gómez Jaramillo y Santiago Martínez Delgado realizaron en el Capitolio Nacional. Bajo el mecenazgo oficial de los gobiernos de López Pumarejo y de Eduardo Santos estos murales buscaban representar la historia colombiana en una construcción que combinaba arte y política, mientras pretendían exaltar valores e ideas de raigambre liberal, presentes en la construcción de la nación colombiana ${ }^{144}$.

En un interés por fomentar un tipo de nacionalismo, el mecenazgo cultural ejercido en ambos países contó con la participación de funcionarios públicos, instituciones, intelectuales y artistas de diversas vertientes que partiendo de múltiples ángulos de acción influyeron en el rumbo que tomó esta política cultural. Tal mecenazgo llegó a involucrar el ejercicio diplomático, en aras de dar un alcance internacional a las iniciativas locales, difundir una imagen de la cultura nacional y de paso establecer conexiones con los demás gobiernos. Así, por ejemplo, la iniciativa que en algún momento tuvo Daniel Cosío Villegas para México consistente en reunir textos referentes a Colombia que abordaran temas ligados con la historia, la geografía, las ideas políticas, la literatura, la poesía, entre otros y hacer un catálogo de publicaciones relativas al país - fue retomada años después por el embajador colombiano Jorge Zalamea como una idea útil para dar a conocer en México los trabajos de escritores colombianos.

De igual manera, un ofrecimiento hecho por el Fondo de Cultura Económica para publicar trabajos de escritores colombianos era visto por Zalamea como un proyecto al que

${ }^{141}$ García, ed., "Políticas culturales y crisis de desarrollo: un balance latinoamericano", 35.

${ }^{142}$ Stephen Niblo, México en los cuarenta. Modernidad y corrupción (México, Editorial Océano, 2008), 79.

${ }^{143}$ En una interesante definición de Helena Wiesner, el muralismo se caracteriza por ser un movimiento heterogéneo producido con apoyo estatal. Desarrolla propuestas visuales autónomas que buscan representar la identidad nacional, apoyarse en la historia propia y occidental y coparticipar del modernismo del siglo XX, en momentos en los que la sociedad que lo produjo se transformaba económica, social y políticamente. Para la autora los murales se conciben como signos que substituyen el referente y como presencia en sí mismos, atravesados por la historia, la política, la ideología y la cultura como características de las representaciones visuales modernas. Para un mayor detalle véase Helena Wiesner, Murales capitolinos de Ignacio Gómez Jaramillo y Santiago Martínez Delgado. (Bogotá, 1938-1948) (Bogotá: Academia Colombiana de Historia, 2014), 16-23.

${ }^{144}$ Wiesner, Murales capitolinos ..., 14. 
podían vincularse personajes de la vida pública nacional, a fin de proyectar a nivel latinoamericano facetas diversas de la cultura colombiana ${ }^{145}$. Aunque nada se sabe de la suerte que corrió esta iniciativa promovida por Zalamea hacia los años cuarenta, si es conocida la cercanía que escritores como Germán Arciniegas tuvieron en distintos momentos de su trayectoria académica con esta casa editorial mexicana. La correspondencia múltiple de sus épocas como funcionario público, ministro de Educación, diplomático, y a través de la circulación de novedades bibliográficas, muestra al ensayista colombiano como fuente de intercambio con escritores mexicanos y suramericanos.

La enseñanza y la política educativa del cardenismo generaban recelos, a pesar de la buena imagen que tenía entre más de un funcionario colombiano el proyecto de difusión cultural de México. La educación primaria fue vista como un espacio controlado y utilizado para afianzar ideas socialistas, razón por la cual, y de acuerdo con algunos funcionarios colombianos, estos planes no resultaban dignos de emular. En informes relativos a la educación en México, enviados a Luis López de Mesa, se hablaba de los proyectos emprendidos por parte del secretario de Educación mexicano Sánchez Pontón en tiempos de mandato del presidente Manuel Ávila Camacho. Esta mirada en torno a la educación pública mexicana y a la iniciativa estatal de generar y de difundir un proyecto nacionalista en escuelas urbanas y rurales, fue visto por el embajador colombiano Jorge Zawadzky como un ejercicio de promoción de ideas comunistas. La crítica que el embajador colombiano hacía al proyecto educativo mexicano centraba su atención en los contenidos de los libros de texto, en sus influencias marxistas y en el papel otorgado a la Secretaría de Educación Pública, como entidad de vigilancia y control de la enseñanza ${ }^{146}$.

\section{La utilidad política de la cultura}

En el escenario colombiano y en el plano de las ideas y de la difusión cultural, la República Liberal fue vista como uno de los más importantes intentos por crear una política cultural institucionalizada durante el siglo XX; a través de la organización de un sistema estable de instituciones culturales en las que los libros, el cine, los museos, las escuelas ambulantes y la radio fueron piezas claves, que al lado de la vinculación de intelectuales pretendió plantear la idea de democratizar el acceso de las mayorías a los bienes culturales del país ${ }^{147}$. La cultura adquirió durante 1930 a 1946 un componente político que la vinculó con lo social, y que buscaba construir nuevas bases espirituales para el Estado y la política nacional, en un momento en que la educación fue un mecanismo idóneo para fortalecer este tipo de iniciativas.

Escritores como Darío Achury Valenzuela y Germán Arciniegas —adscritos a dependencias oficiales - resultaron claves en este proyecto político de formación y difusión de una cultura popular colombiana. Algunas instituciones públicas ya existentes fueron reorganizadas: la promoción de bibliotecas municipales y los cambios efectuados en el Ministerio de Educación Nacional resultaron de este replanteamiento de lo popular. De acuerdo con Renán Silva:

\footnotetext{
145 Archivo General de la Nación Colombia. Fondo Cancillerías (AGNC-FCOI). Informe sobre proyecto de intercambio cultural, enero 31 de 1944.

146 AGNC-FCOI. Carta a Luis López de Mesa, enero 27 de 1941.

${ }^{147}$ Renán Silva, República Liberal Intelectuales y Cultura Popular (Medellín: La Carreta, 2005 ), 62.
} 
... Cuando decimos que la Republica Liberal "inventó" la cultura popular no estamos diciendo que antes de tal designación el fenómeno no tuviera antecedentes en la historia cultural del país. Lo que queremos decir es, concretamente, que la Republica Liberal concretó, sintetizó y desplegó bajo nuevas significaciones una evolución en curso cuyo resultado no era, por lo demás, necesariamente y de manera previamente determinada, ese proceso de designación. Por fuera de una cierta política de masas y de una forma precisa de plantear las relaciones entre el pueblo y la elite, la configuración cultural llamada "cultura popular" no hubiera adquirido las modalidades precisas que le han sido distintivas desde entonces, y que se concretan en su definición a través de una serie de rasgos culturales identificables... ${ }^{148}$.

De modo similar a lo ocurrido en México durante este mismo periodo, en Colombia el nacionalismo cultural vino a fomentar espacios de unidad nacional que permitieron la inclusión de tradiciones populares en el desarrollo de proyectos de reafirmación de identidades. Los primeros gobiernos de la Republica Liberal encontraron en la política cultural un medio viable para generar consenso y acercarse de una mejor manera a poblaciones dispersas en el ámbito de la vida regional. De ahí, que difundir un sentimiento nacional vinculante resultaba ser un proyecto políticamente útil, al que ayudaba la promoción del folclor, de la música, la danza, la recitación popular, el canto, el baile, las artes dramáticas, los conciertos abiertos y el establecimiento de bibliotecas en pueblos y ciudades colombianas.

En México también durante esta etapa, y con marcados precedentes heredados de los primeros gobiernos posrevolucionarios, la revalorización de lo popular, los énfasis en la cultura y en el pasado indígena fueron parte de un amplio proceso de apertura que dio cabida a nuevos actores en el escenario político. En medio de la promoción de nacionalismos culturales, lo mexicano fue interpretado como un campo útil a la difusión de un proyecto político, viable de difundir por vías como el arte, la educación y las expresiones culturales de las mayorías ${ }^{149}$. La mirada hacia un pasado lejano y hacia la grandeza de la vida prehispánica y de sus manifestaciones servían como escenario articulador de la identidad mexicana al situar desde la historia un proyecto político y una noción de inclusión social. En este proceso, el ethos de lo indio, lo campesino y lo urbano fueron entre otros, algunos de los factores visibles de una nueva construcción social, revestida de un ideal de unidad patriótica ${ }^{150}$.

En este proyecto la vinculación de intelectuales, artistas y escritores al ramo de la diplomacia y el gobierno fue un acontecimiento frecuente. Permitió difundir nuevos imaginarios y construcciones identitarias en torno a la política y a la cultura mexicana. Paralelo a la ofensiva diplomática que buscaba el reconocimiento internacional de los gobiernos posrevolucionarios, gran parte de la labor de los intelectuales y de los artistas se dedicó al establecimiento de vínculos culturales, que en el largo plazo dieron a la revolución una dimensión continental ${ }^{151}$. Tal propósito de difusión otorgó a la cultura mexicana un valor político susceptible de ser expuesto en distintos países latinoamericanos. El idioma, la historia, la literatura y las tradiciones sirvieron de puntos de encuentro a las intenciones gubernamentales $^{152}$. Figuras como las de Jaime Torres Bodet, Daniel Cosío Villegas, Alfonso

\footnotetext{
${ }^{148}$ Silva, República Liberal Intelectuales..., 17.

${ }^{149}$ Ricardo Pérez, Estampas de nacionalismo popular mexicano. Ensayos sobre cultura popular y nacionalismo (México, D.F: CIESAS, 1994), 71.

${ }^{150}$ Alan Knight, "Racismo, revolución e indigenismo: México, 1910-1940”, Repensar la Revolución Mexicana II, El Colegio de México (2004): 9-42.

151 Pablo Yankelevich, La Revolución mexicana en América Latina. Intereses políticos e itinerarios intelectuales (México: Instituto Mora, 2003), 18.

${ }^{152}$ Mariano Picón-Salas, "Lo hispanoamericano desde los Estados Unidos", Cuadernos Americanos 15, mayojunio (1944): 59-60.
} 
Reyes, Genaro Estrada y Palma Guillen resultan familiares al ámbito de las relaciones internacionales, al desempeño de cargos diplomáticos, a la academia y a las letras mexicanas ${ }^{153}$. A este ejercicio diplomático se sumaron también poetas como Efrén Rebolledo, quien murió hacia 1929 en momentos en que se desempeñaba como parte del cuerpo diplomático mexicano acreditado en España ${ }^{154}$. También figuran en este listado de intelectuales vinculados al ramo de la diplomacia mexicana, el escritor yucateco Miguel Ángel Menéndez, quien fuera embajador de México en Colombia hacia 1943, momento en que relevó de su cargo al militar Federico Montes.

Igualmente, nombres como los de Isidro Fabela, Amado Nervo, Jesús Urueta, al lado de personajes que recorrieron Suramérica en el desempeño de distintas comisiones, como fuera el caso de Luis Urbina, Luis Cabrera, Antonio Caso, José Vasconcelos, Genaro Fernández MacGregor, Julio Torri, Antonio Médiz Bolio, entre otros, se suman a este proyecto de difusión cultural e intelectual ${ }^{155}$. El propósito de estas comisiones era la de difundir en el exterior ideas y proyectos nacionales en escenarios públicos, universitarios y en espacios gubernamentales. Estas giras de propaganda tenían la finalidad de dar a conocer proyectos de integración discutidos en cuerpos colegiados mexicanos, políticas agrarias, proyectos educativos y planes de cooperación internacional. Así pues, la idea de difundir por todo el continente aspectos positivos de la administración del México posrevolucionario, permeaba el ámbito diplomático, académico y político colombo mexicano. Visitas de estudiantes y profesores a la capital mexicana, así como el intercambio de literatura proveniente de ambos países, eran acontecimientos frecuentes en este diálogo binacional.

En este contexto, a finales de julio y principios de agosto de 1934, el encargado de negocios de la legación mexicana Salvador Navarro Aceves, visitaba las ciudades colombianas de Cali, Popayán y Manizales con el objeto de dar conferencias en torno al problema agrario, el movimiento artístico y la Revolución mexicana ${ }^{156}$. Navarro Aceves hizo una exposición sobre el problema de las tierras en México. Su informe daba cuenta de la impresión que algunos sectores intelectuales y políticos de las ciudades visitadas tenían de la Revolución mexicana, además de la propaganda negativa que de ella hacían religiosos y algunos periódicos conservadores. De acuerdo con el informe del mismo Navarro Aceves, entre la audiencia estaba el político y escritor caucano Guillermo Valencia, al lado de personajes del ámbito universitario y político de Popayán, con quienes Navarro compartió visiones y perspectivas en torno al gobierno y al país que representaba. Esta visita, se produjo en un momento reciente al final de la guerra de Colombia con el Perú y aparece reseñada en los informes de la legación mexicana, al lado de resoluciones, comunicaciones y reclamos presentados ante la Liga de las Naciones por parte de diplomáticos colombianos. Los informes enviados por el ministro plenipotenciario acreditado en Colombia Óscar E. Duplán daban cuenta de este tipo de acontecimientos, en tanto que sus funciones como parte de la diplomacia mexicana lo acercaban al presidente electo López Pumarejo, en el desarrollo de viajes internacionales y en la celebración de actos públicos.

\footnotetext{
153 Para un mayor detalle véase Aurelio de los Reyes, Escritores en la diplomacia mexicana (México: SRE, 1998).

${ }^{154}$ Rebolledo ejerció este cargo en Madrid junto al entonces jefe de legación Enrique Gonzales Martínez y del entonces secretario Jaime Torres Bodet. El Tiempo, 1 de febrero de 1930, 4, Lecturas Dominicales.

155 Yankelevich, La Revolución mexicana en América Latina... 18.

${ }^{156}$ AGE-SRE. Informe 8 de agosto de 1934. Años antes y hacia julio de 1929, Salvador Navarro Aceves aparecía referenciado en el periódico colombiano El Tiempo, por medio de la publicación de un artículo que expresaba algunas de sus reflexiones en torno a la situación de México. El Tiempo, 3 de julio de 1929, 9.
} 


\section{La pantalla grande y la difusión de una nueva imagen}

Los años treinta y cuarenta, representaron un importante momento para la difusión del cine mexicano más allá de sus fronteras, dado que sus producciones pudieron ser vistas en distintas ciudades sudamericanas, con la proyección de cintas que reflejaban aspectos de la cultura y del folclor. Como se ha venido insistiendo, para este momento histórico, la revisión de la cultura y la idiosincrasia mexicana iniciada a partir de los años veinte encontró en el nacionalismo cultural una importante fuente de recursos para reivindicar valores de raigambre popular y expresiones que colocaban al "pueblo mexicano" en el centro del debate artístico, académico e intelectual ${ }^{157}$. En esta revisión, el cine permitió proyectar una imagen de la cultura mexicana y de las costumbres de sus pobladores. Lo que construyó en el exterior un estereotipo en el que la música, el melodrama y las historias múltiples del cine de la época de oro recorrieron el continente americano ${ }^{158}$.

Esta simplificación de la realidad, asociada a charros, canciones rancheras y a historias del campo mexicano fue conocida en Colombia durante los años treinta y cuarenta, en un momento en que la producción cinematográfica mexicana gozaba de una amplia audiencia a lo largo del continente americano. Como parte de este amplio proyecto de difusión canalizado por vías como las artes, el cine fue visto y utilizado como un importante instrumento de propaganda que elevó a la categoría de mitos culturales en las audiencias latinoamericanas a distintos personajes presentes en el cine de charros, canciones y melodramas, presentados bajo los esquemas del star system de Hollywood ${ }^{159}$. Para Aurelio de los Reyes, la producción cinematográfica de este periodo encontró en el teatro, en el paisajismo y en la literatura costumbrista una importante fuente de inspiración. Permitía recrear y difundir formas diversas de propaganda nacionalista que durante los años treinta hicieron posible la continuidad de temas y actitudes que otrora habían sido abordadas por el cine mudo ${ }^{160}$.

Exaltar la historia nacional y otorgar una mirada sobre las tradiciones y las prácticas culturales de la mayoría de los mexicanos fue en este periodo un elemento clave para canalizar una idea y dar difusión a este proyecto político afianzado a partir de los años veinte. El impacto internacional y los traumatismos generados por la Revolución mexicana habían deteriorado considerablemente la imagen de México, asociándola al caos y al desorden social, en un momento en que la producción cinematográfica estadounidense contribuía a fortalecer esta imagen mediante asociaciones al salvajismo y al bandidaje vivido en el otro lado de su frontera sur. Serguéi Eisenstein tuvo una influencia definitiva en la carrera y en la producción de varios directores y fotógrafos mexicanos de esta época. El Indio Fernández; el camarógrafo, Gabriel Figueroa; el guionista, Mauricio Magdaleno; al lado de actores como Pedro Armendáriz, divas como Dolores del Río y María Félix, entre otros, resultan de gran valor para la historia del cine mexicano en su época de oro, en la medida en que difundieron la idea de un México estereotipado y cargado de una mexicanidad que exaltaba el nacionalismo y el exotismo de sus tierras y de sus sociedades en una dimensión premoderna y rural ${ }^{161}$. Para el caso del Indio Fernández, se descubría en sus películas una "esencia

\footnotetext{
${ }^{157}$ Pérez, Estampas de nacionalismo popular mexicano... 140.

158 Miquel Rodrigo Alsina, "Elementos para una comunicación intercultural", Revsia cibod d 'Afers Internacionals $\mathrm{n} .{ }^{\circ} 36$ (1997), 7.

${ }^{159}$ Miguel Ángel Flórez, Mario Moreno Cantinflas. El filósofo de la risa (Bogotá: Editorial Panamericana, 2005), 43-44.

${ }^{160}$ Aurelio Reyes, Medio siglo de cine mexicano (México: Editorial Trillas, 1987), 130.

${ }^{161}$ Ricardo Pérez, Cotidianidades, imaginarios y contextos: ensayos de historia y cultura en México. 18501950 (México: CIESAS, 2008), 314.
} 
mexicanista" muy acorde con el discurso oficial de exaltación de lo propio. Varias producciones mostraban diversos paisajes y contrastes de un México en los que el drama nacional, la injusticia y las imágenes de sus pobladores forjaron un imaginario de la cotidianidad de campos y regiones mexicanas. Películas como Janitzio (1934) del director Carlos Navarro; Allá en el rancho grande (1936) de Fernando de Fuentes, en la que se bailaba un jarabe tapatío; Ora Ponciano de Gabriel Soria (1936); Jalisco nunca pierde (1937); Adiós Nicanor (1937); ;Ay Jalisco, no te rajes! (1941); la serie de El charro negro (1940 en adelante); María Candelaria (1943); La Perla (1945); Me he de comer esa tuna (1945); Río escondido (1947); Pueblerina (1948). Para Miguel Ángel Flórez, el cine mexicano ofreció, en la producción masiva de melodramas y comedias habladas en español, elementos de identidad que fácilmente fueron recibidos por sociedades en procesos de construcción de su nacionalidad $^{162}$.

En el periódico El Tiempo, ;Ay Jalisco, no te rajes! era promocionada como la película que lo tenía todo: "Música, canciones, romance, acción, emoción, calor, intriga y buen humor". Su estreno en el teatro Real de Bogotá era anunciado como un grato acontecimiento para el público colombiano ${ }^{163}$. Estas producciones fílmicas de charros cantores, chinas bailadoras envueltas en historias de amor; al lado de pistolas, caballos, palenques, guitarras y sarapes, dieron un sello particular a las producciones de la época de oro del cine mexicano, mientras mostraban variadas facetas del folclor regional. Estas películas posicionaron la imagen del Bajío, del centro de México y en especial de la región de Jalisco como los escenarios privilegiados del charro mexicano, mientras apuntalaban las carreras de artistas como Jorge Negrete y Pedro Infante.

Este cine de charros contribuyó a fortalecer un nacionalismo vacío, fuertemente sujeto a las concepciones de una historia oficial de clara raigambre conservadora y autoritaria ${ }^{164}$. De modo similar a lo proclamado por los libros de texto oficial en torno al ideal de un solo país, con un solo territorio, con una sola historia y con un solo lenguaje; a partir de los años treinta, el cine mexicano también sirvió a estas consignas de raigambre nacionalista para difundir la idea de un México culturalmente homogéneo. Fue un momento en que la producción cinematográfica mexicana conoció un interesante proceso de internacionalización, industrialización y formación de audiencias, que hizo posible su reconocimiento en un contexto mediado por pautas de apropiación social.

En este periodo películas como Allá en el rancho grande estrenada en 1936, alcanzaron proyección internacional y como buena parte de las producciones mexicanas lograron ser distribuidas en Colombia en distintas salas y ciudades del país. Competían de modo abierto por la audiencia latinoamericana con producciones de Hollywood, España y Argentina. Esta película de Fernando de Fuentes otorgó al cine mexicano su primer premio internacional de fotografía y popularizó a Tito Guízar como cantor ranchero en toda Latinoamérica, mientras abrió insospechados mercados para el cine nacional, gracias a la buena combinación del drama con las composiciones de Lorenzo Barcelata y a la versión triunfalista de la canción Allá en el rancho grande ${ }^{165}$. Exitosa en México, en la España franquista y premiada en el festival de Venecia, esta película difundía un temor que fácilmente podía insertarse en el seno de estas sociedades, en un momento en que sus sistemas políticos daban significativos giros

${ }^{162}$ Flórez, Mario Moreno Cantinflas..., 50.

${ }^{163}$ El Tiempo, 3 de diciembre de 1941.

${ }^{164}$ Pérez, Cotidianidades, imaginarios y contextos..., 320.

165 Yolanda Moreno, Historia de la música popular mexicana (México, D.F.: Alianza Editorial Mexicana, 1979), 80. 
hacia el fascismo en el marco de una coyuntura económica, en la cual la producción cinematográfica mexicana junto al petróleo, representaban una importante fuente de divisas $^{166}$.

Para Aurelio de los Reyes, esta película expresaba una nostalgia por un pasado inmediato, hacía evidentes críticas al agrarismo revolucionario, mientras abogaba por la tradición, el conservadurismo y la preservación de las costumbres ${ }^{167}$. Además de esta película, el melodrama ranchero permitió la apertura de nuevos mercados para su comercio, acercaron al público hispanohablante con historias de su entorno, mientras daban a conocer la cultura mexicana y diversas vivencias, a veces musicalizadas en la voz de sus protagonistas. Este tipo de producciones, catalogadas por Emilio García Riera como un tipo de comedia folclórica, fue un formato muy frecuente en el cine mexicano de los años treinta. Para García Riera, la comedia folclórica reflejaba vivencias de una clase media incipiente que situaba en el centro de sus preocupaciones una defensa de las tradiciones y una visión conformista, muchas veces alejada de la verdadera vida social del país ${ }^{168}$.

De acuerdo con Angie Rico, mientras el cine mexicano se abría camino en Colombia, la música ranchera ganaba aceptación en las recién creadas emisoras del país, en un proceso que transformó los modos de recibir información y en el que el cine mexicano reflejaba aspectos compartidos de su cultura proyectando situaciones que resultaban familiares al espectador $^{169}$. A diferencia del cine francés o hollywoodense, el cine mexicano permitía, a partir del idioma y con sus melodramas, una conexión fácil y cercana con públicos que en su mayoría no sabían leer, y a los que las historias del cine norteamericano o europeo les resultaban lejanas y distantes. A su vez, comedias como Ahí está el detalle (1940) y Ni sangre ni arena (1941) de Cantinflas, gozaron de abundante promoción en los espacios destinados a difundir la cartelera cinematográfica bogotana, en medio del prestigio que paulatinamente iban ganando sus producciones y de la acogida que lograban tener entre el público colombiano.

Curiosamente y junto al anuncio de Ahí está el detalle se ofertaba un talismán con la figura del personaje de la película, el cual era promocionado como un objeto útil para atraer la buena suerte y la alegría entre los compradores ${ }^{170}$. Sucesivas películas de Cantinflas como El gendarme desconocido (1942), El circo (1942), Los tres mosqueteros (1943), Soy un prófugo (1946) y muchas otras realizadas durante los años cuarenta, lograban acaparar la atención de la prensa y de los anuncios encargados de difundir la cartelera cinematográfica promocionada en las salas de Bogotá y de otras ciudades del país. Películas como Cabalgata de honor (1942) de Raúl de Anda, en la que participaba Domingo Soler, Lucha Reyes, Susana Cora, Emilio Fernández y Pedro Armendáriz, también entraron a nutrir la cartelera de películas mexicanas promocionadas junto a producciones en su mayoría estadounidenses ${ }^{171}$.

Por otra parte, el consumo de cine mexicano en Colombia, durante finales de los años treinta e inicios de los cuarenta, hizo posible un aprendizaje que corrió paralelo a la idea institucionalizada promovida por el gobierno liberal, por vías como la escuela, las bibliotecas ambulantes y el fonógrafo. Este aprendizaje fue posible gracias a la recepción de un mundo

\footnotetext{
166 De los Reyes, Medio siglo de cine mexicano..., 153.

${ }^{167}$ De los Reyes, Medio siglo de cine mexicano..., 154.

168 Emilio García, El cine mexicano (México: Ediciones Era, 1963), 26.

169 Angie Rico, Bucaramanga en la penumbra. La exhibición cinematográfica 1897-1950 (Bucaramanga: Universidad Industrial de Santander, 2013), 135-136.

${ }^{170}$ El Tiempo, 13 de agosto de 1941.

171 El Tiempo, 8 de marzo de 1942, 15.
} 
fácilmente asimilable, en el cual el público encontraba referentes de complicidad en las historias y en los melodramas que el cine mexicano proyectaba y que lograron una apropiación social en los sectores populares. El uso social del cine de barrio escenificó las prácticas de un proceso colectivo de autocomprensión, al cual se iba a aprender estilos de vida y estilos de ser pobre, se iban a aprender los usos amorosos y las soluciones melodramáticas a los conflictos de la vida y se aprendía también el lugar social de cada uno, en un mundo que se urbanizaba rápidamente ${ }^{172}$. De acuerdo con Chica:

... el proceso de apropiación consistió en un regodeo de la cultura popular y sus expresiones, en virtud de la complicidad del público con los relatos de las películas, en otros términos, la gente resignificó los contenidos fílmicos según negociaciones de sentido caracterizadas por su ambigüedad y por su ironía, donde el humor y el melodrama fueron los referentes operacionales principales. Resignificar los contenidos fílmicos supuso un reciclaje cultural que contribuyó en los procesos de supervivencia de las gentes, pues, por su parte las películas contaron y enseñaron las verdades de la vida; y, las canciones de los artistas se convirtieron en las bandas sonoras de la vida de las personas y en su trasegar por el padecimiento y la resignación, el sufrimiento y el aguante, la rabia y la contención, la esperanza y la desilusión, la risa y el llanto... ${ }^{173}$.

A nivel general, títulos como El tesoro de Pancho Villa (1935), La Pajarera (1945), Corazones de México (1945), al lado de artistas y cantantes mexicanos como Pedro Vargas, Pedro Infante, José Mojica, Gustavo Rojo, Domingo Soler y la tabasqueña Lilia Michel, eran conocidos en Colombia gracias a su actuación en la pantalla grande y a las giras de conciertos que promovían empresarios particulares a la par de la organización de espectáculos. Igualmente, los cantantes mexicanos partícipes de algunas de estas películas anunciaban sus conciertos en periódicos de circulación nacional y se presentaban en teatros capitalinos, en los que exhibían su repertorio de canciones, algunas de estas conocidas por la difusión que de ellas hacían algunas de las estaciones de radio existentes en el país como la Radiodifusora Nacional.

Bajo esta visible utilidad del cine como medio de propaganda, realizar una corta película que diera a conocer algunas ciudades colombianas y ayudara a difundir una imagen del país en México fue una de las propuestas del embajador Luis Eduardo Nieto Caballero al Ministerio de Relaciones Exteriores hacia 1948. La propuesta del funcionario, que no se materializó, contemplaba un contrato con la empresa Orpe Films de México, con el objeto de realizar una corta producción en la que además de mostrar facetas de algunas de las principales ciudades, se resaltasen aspectos productivos entre los que podría entrar el cultivo del café, los textiles, las industrias tabacaleras, la agricultura y la extracción minera. Según el informe, esta producción tendría un costo cercano a los ocho mil dólares, que según Nieto Caballero podrían ser financiados con la ayuda de empresas privadas con el fin de fomentar el turismo y dar publicidad en el extranjero a las ciudades y a las empresas nacionales. De acuerdo con el embajador, la Orpe Films ya tenía experiencia en la realización de documentales en Colombia, al haber desarrollado un trabajo que daba cuenta de los Juegos Centroamericanos y del Caribe de 1946 en Barranquilla y un corto sobre algunas calles de Cartagena, que tiempo después esta empresa proyectó en algunos teatros mexicanos ${ }^{174}$. Este

172 Ricardo Chica, "La apropiación social del cine mexicano de la época de oro en Cartagena de Indias, Colombia 1936-1957" (ponencia leída en el II Encuentro de Estudios Históricos Comparados MéxicoColombia, UPTC, Tunja, agosto de 2014), 5.

${ }^{173}$ Chica, "La apropiación social del cine mexicano de la época de oro en Cartagena de Indias, Colombia 19361957 ", 9.

174 AGNC-FCOI. Informe del embajador Luis Eduardo Nieto Caballero, octubre 23 de 1948. 
intento por proyectar una imagen de Colombia en México y en otros países del exterior era vista como un mecanismo que para este mismo momento utilizaban países como Argentina y Chile con el fin de dar a conocer en México aspectos de su cultura nacional.

A pesar de la audiencia y de la amplia difusión que tenía el cine mexicano en las salas colombianas, el proceso de ingreso de las películas a territorio nacional tropezaba con algunos obstáculos tributarios desventajosos para las producciones mexicanas. Santiago Reachi, presidente de la Asociación de Productores y Distribuidores de Películas Mexicanas, solicitó, por conducto del encargado de negocios de la embajada colombiana, una rebaja en el impuesto que las películas pagaban a la hora de ingresar al país para ser distribuidas en distintas ciudades y salas de proyección. La petición de Reachi, se sustentaba en los elevados costos que debían pagar las producciones mexicanas y las de habla hispana con relación al impuesto que pagaban las producciones norteamericanas y las hechas en otros idiomas. Para el representante de los productores mexicanos, mientras una película en lengua distinta de la española pagaba un costo de 0,60 pesos por kilogramo en impuestos de importación, una película en español pagaba 1,20 pesos por ese mismo concepto, situación que consideraba injusta. Esta razón lo motivaba a solicitar ante la embajada su mediación ante el Gobierno colombiano, para equilibrar los costos en el ingreso de las películas extranjeras al país.

De la suerte que corrió la petición de Reachi nada se sabe. Otras comunicaciones llegadas a la embajada en distintas fechas abordaban situaciones similares, algunas de ellas relacionadas con los altos costos de los materiales utilizados en la producción de películas y de las dificultades en la distribución del cine mexicano en algunas ciudades colombianas ${ }^{175}$. Por otro lado, las ganancias que el cine mexicano alcanzaban en América Latina durante la primera mitad de la década del cuarenta eran vista como una de las principales y directas competencias para la industria de Hollywood. La acogida entre las audiencias de países de centro y Suramérica, junto a la fama que ya tenían los artistas mexicanos fueron los principales factores que contribuyeron a la pérdida de importantes mercados para los productores norteamericanos, quienes en su momento establecieron estudios en México para aprovechar las ventajas disponibles, recuperar terreno y producir historias en lengua castellana ${ }^{176}$.

Además de la oferta de películas mexicanas y como parte del intercambio continuo de espectáculos llegados de México durante principios de los cuarenta, algunos toreros mexicanos tuvieron oportunidad de actuar en plazas colombianas con publicitadas y comentadas corridas que reunían a los aficionados al espectáculo taurino ${ }^{177}$. Estas corridas resultaban ser un espectáculo frecuente no solo en Bogotá. La tauromaquia contaba con una amplia resonancia en las páginas de periódicos y revistas que daban cuenta de la amplia afluencia de espectadores a las corridas, promocionadas con anticipación en los anuncios publicitarios. Toreros mexicanos como Juanito Vela, David Liceaga, la rejoneadora chilena Conchita Cintrón y un nutrido cartel de toreros españoles y de diversos lugares tuvieron oportunidad de actuar en distintos momentos en la Plaza de Toros de Santamaría de Bogotá. Otros toreros mexicanos que tuvieron oportunidad de actuar en Bogotá, en posteriores temporadas taurinas, fueron Tato de México, Pepe y Emiliano Vela, quienes en tardes taurinas lidiaban toros de ganaderías colombianas. Las reseñas en la prensa despertaban

175 AGNC-FCOI. Carta de Santiago Reachi a José Joaquín Gori, encargado de negocios de la embajada colombiana en México, 1 de enero de 1943.

${ }^{176}$ El Espectador, marzo 15 de 1944, p. 5.

${ }^{177}$ El Espectador, septiembre de 1934. Anuncio publicitario. 
múltiples comentarios, mientras daba cuenta de la importancia de este tipo de espectáculos para la sociedad capitalina ${ }^{178}$.

Junto al anuncio de futuras corridas a cargo de un grupo de toreras mexicanas, en la Plaza de Toros de Santamaría y con novilleros nacionales, actuó también el torero mexicano Paco Gorraez, quien despertaba buenos comentarios en la prensa por su estilo, sus formas de lidiar los ejemplares y por su conexión con el público bogotano ${ }^{179}$. La visita de esta cuadrilla de jóvenes toreras mexicanas y su presentación en dos tardes, con toros de la ganadería El Pedregal, fue un evento que se venía anunciando durante el segundo semestre de 1944, pero que ocurrió meses después. Entre Las señoritas toreras figuraban Lupita Montes, La virgen de los ruedos; Teresita Montero, La faraona del estilo; Elisa Gallardo, La sobresaliente, junto a las banderilleras Esperanza García; Yolanda Trascierra, La loca; Gloria García y Eva Belmonte $^{180}$. De acuerdo con las impresiones de la prensa, las dos primeras corridas gozaron de buenos comentarios, mientras que la tercera resultó ser todo un fracaso en vista de la calidad de los toros y del espectáculo ofrecido por las mexicanas, según la crítica no estuvieron al nivel de otros espectáculos taurinos ${ }^{181}$.

Como parte de este tipo de eventos que continuamente se ofrecían en la Santamaría, el mexicano Mario Moreno, Cantinflas, en una de sus giras por Suramérica, tuvo oportunidad de ofrecer una tarde de toros. Lidió algunos becerros ante un numeroso público, el espectáculo incluía baile. Su presencia y la exhibición de sus dotes como torero bufo fueron un acto de grata recordación en la prensa de la época ${ }^{182}$. Además de este espectáculo cómicotaurino, promocionado con anticipación en la prensa, se sabe que el actor hizo varias presentaciones en otras ciudades del país en las que actuaba junto a un elenco de artistas que acompañaban sus espectáculos. Actores y músicos entre los que figuraba Estelita Mejía, Paquita Estrada, Estanislao Shavilsky y Jorge Rachini fueron parte de esta gira de presentaciones que incluía a países como Argentina y Perú ${ }^{183}$.

Los conciertos, los espectáculos taurinos, la proyección de películas representativas de la época de oro y la difusión que emisoras y productoras musicales, como la RCA Víctor, daban a la música popular mexicana resultaron frecuentes en la publicidad y en las carteleras de espectáculos anunciadas en las páginas de periódicos colombianos. Junto a la promoción de toreros, la estancia de circos mexicanos como el Atayde Hermanos también se sumaban a la oferta de actividades de distracción que esporádicamente llegaban a Bogotá y utilizaban la Plaza de Toros de Santamaría como punto de encuentro. Espectáculos de baile, comedia, música y la exhibición de animales salvajes eran promocionados como parte de lo que ofrecía al público este circo mexicano, anunciado en su momento como un espectáculo de alta calidad apreciado en otras ciudades del continente ${ }^{184}$.

El cine y la música popular mexicana se convirtieron en un interesante binomio que acompañó y reprodujo los dramas y los espacios recreados en las películas, muchas de las cuales llevaban el nombre de la canción que les servía de banda sonora. La promoción de canciones resultó ser un acontecimiento frecuente en las salas colombianas, en el que interpretaciones de artistas como Tito Guízar eran promocionadas entre la audiencia y el

${ }^{178}$ El Tiempo, 28 de noviembre de 1942, 15.

${ }^{179}$ El Espectador, 4 de septiembre de 1944, 7.

${ }^{180}$ El Espectador, 26 de mayo de 1945, 6.

${ }^{181}$ El Espectador, 15 de junio de 1945, 7.

182 El Tiempo, 23 de marzo de 1943, 2.

${ }^{183}$ El Tiempo, 25 de marzo de 1943, 1 y 7.

${ }^{184}$ El Tiempo, 22 de diciembre de 1941, 16. 
público. Canciones como Sueño de amor, Trovador, Mujeres latinas, Cantor del pueblo y Presumida eran presentadas junto a las películas, mientras servían para promocionar producciones musicales recientes ${ }^{185}$. Algunas de las producciones que contaron con la aparición de José Mojica mostraban una situación similar; se presentaban canciones como Solamente una vez y otras composiciones de Agustín Lara, en un formato proyectado en las salas de cine colombianas. La música y algunas canciones latinoamericanas representativas de la época resultaban ser el ingrediente principal de estas proyecciones ${ }^{186}$.

Este binomio de cine y música popular que afianzaba el éxito de cantantes famosos y canciones de moda, que acompañaban a veces los títulos de las películas, también hizo posible el fomento de una industria dedicada a la composición, en la que participaron creativos, guionistas, actores, cantantes y músicos de diversas regiones mexicanas. Nombres como los de Manuel Esperón, Ernesto Cortázar, Manuel Castro Padilla, Joaquín Pardavé, Lorenzo Barcelata, Agustín Lara conocido como El flaco de oro, Felipe "Charro" Gil, el trio Medellín, el trio Hidalguense, Gonzalo Curiel, Miguel Lerdo de Tejada, Pedro Junco y varios compositores de boleros resultan muy cercanos a la producción cinematográfica del México de los años treinta y cuarenta ${ }^{187}$. En este tipo de producciones, la presencia de cantantes como Tito Guízar, Jorge Negrete en películas como Historia de un gran amor (1942), Pedro Infante, Pedro Vargas, Chucho Martínez Gil y tiempo después José Alfredo Jiménez, junto a una larga lista de artistas, resultaban funcionales al esquema utilizado en la producción cinematográfica, en la medida en que lograban combinar sus dotes artísticos con la actuación, mientras sus canciones apoyaban y rápidamente popularizaban las películas ${ }^{188}$.

\section{Radio, noticias y canciones}

Tanto al interior del territorio nacional como fuera de él, las canciones y los artistas que la emergente industria discográfica, el cine y la radio promocionaban lograron pronto convertirse en un referente del folclor nacional. En Colombia, por vías como la radio fue posible la difusión de voces y de canciones venidas de otros escenarios latinoamericanos, en un proceso que hacía viable la apropiación en el vivir cotidiano de ritmos y de letras cercanas con temáticas diferentes. Tanto en México como en Colombia, la irrupción de la radio en los hogares trajo consigo múltiples cambios en la vida cotidiana, en las formas de sociabilidad y en las pautas de consumo cultural, que progresivamente transformaron los modos de recibir información y de apropiar nuevas ideas y contenidos. Escuchar una caja que emitía sonidos venidos de la distancia se convirtió en un acontecimiento. Paulatinamente reemplazó las tertulias y los tradicionales espacios de socialización de las personas ${ }^{189}$.

De la mano de la aparición de la corriente eléctrica, la llegada de la radio a las ciudades y a los hogares se convirtió en un importante fenómeno histórico, en el que convergen adelantos tecnológicos, ideas, sonidos, percepciones y formas de difusión. Desarrollo e

\footnotetext{
185 El Tiempo, 10 de febrero de 1940, 8.

${ }^{186}$ El Tiempo, 27 de agosto de 1942, 15. Anuncio de "Melodías de América" de Estudios San Miguel.

${ }^{187}$ Moreno, Historia de la música popular mexicana..., 82-83.

188 Yolanda Moreno Rivas ofrece un importante listado de personajes ligados a partir de la música con la industria cinematográfica a partir de los años treinta. Agrupaciones, tríos, voces femeninas, compositores, actores y cantantes se suman a este inventario que permite comprender sus vínculos con la radio mexicana. Para mayor detalle véase Moreno, Historia de la música popular mexicana..., 90-97.

189 Rosalía Velázquez, "La radiodifusión mexicana: encuentro con su pasado (1923-1945)”, en Miradas sobre la nación liberal: 1848-1948. Proyectos, debates y desafíos. Formar e informar: la diversidad cultura, libro 2, Josefina Mac Gregor (México: Universidad Nacional Autónoma de México, 2010), 280-281.
} 
impulso que pronto convirtieron a la radio en una empresa comercial ${ }^{190}$. En México, el surgimiento de estaciones radiales durante los años veinte hizo posible la promoción musical por la vía de los radio conciertos, junto a la difusión de espacios dedicados al teatro y al esparcimiento, con programas que abordaban temáticas de interés familiar. Además de ser un referente que cambió la vida cotidiana de los mexicanos — mientras creaba identidad y sentidos comunes - , la radio fue un espacio que hacia el exterior y junto al cine logró consolidar un imaginario construido a través de múltiples mecanismos, que dieron lugar a dimensiones simbólicas, elaboradas a partir de experiencias individuales dotadas de un valor $^{191}$.

Escuchar en países centroamericanos y suramericanos melodías mexicanas interpretadas en la voz de cantantes como Agustín Lara y Pedro Vargas fue posible gracias a la emergencia de estaciones radiales en distintos países del continente. Estos espacios radiofónicos, que a partir de los años veinte empezaron a popularizarse en distintas ciudades latinoamericanas, facilitaron el conocimiento de nuevos ritmos entre las audiencias y permitieron que la música de países como Argentina y Cuba fuera conocida en México, mientras que las canciones del repertorio popular mexicano lograron ser escuchadas en otras latitudes. Boleros, tangos y canciones habaneras entraron en los espacios radiales del continente, generando un interesante intercambio musical, que con el pasar del tiempo hizo frecuente el tránsito de artistas mexicanos y latinoamericanos. Estos escenarios de difusión de la producción artística mexicana por vías como el cine y la radio marcharon de modo paralelo con el paulatino crecimiento de sus audiencias en territorio colombiano. La radio se convirtió en un medio de movilización política útil a la defensa de intereses de líderes liberales y conservadores como Alfonso López y Laureano Gómez durante la década del treinta, en tanto que propagaba nuevas manifestaciones del gusto popular y contribuía, junto al cine, a la secularización de las costumbres ${ }^{192}$. Hacia 1935, la influencia de emisoras cubanas, argentinas y mexicanas - como La XEW, "la voz de América Latina desde México”, propiedad de Emilio Azcárraga - fue notoria en los primeros años de la radiodifusión colombiana, a partir de la sintonía y reproducción de una parte de su programación en cadenas nacionales, en las que la voz de algunos de sus locutores era conocida en las ciudades colombianas que reproducían su señal ${ }^{193}$.

En cuanto a la difusión musical, la llegada a Colombia de la Cadena Kresto en 1940, de la mano de Juan Carlos de Ambrosi, hizo posible la presentación en vivo de artistas mexicanos como Lupita Palomera, Chucho Martínez Gil, el dueto de las Hermanas Águila, al lado de cantantes cubanos, argentinos y venezolanos, que gracias al poder adquisitivo de Kresto lograban ser difundidas en ciudades como Buenos Aires, La Habana, Río de Janeiro, Caracas y distintas ciudades mexicanas en las que la cadena poseía estaciones filiales ${ }^{194}$. Esta cadena radial y la empresa Cine Colombia hicieron posible la primera presentación en suelo colombiano del cantante Pedro Vargas, la cual se pensó con miras a la inauguración del Teatro Colombia - hoy Teatro Jorge Eliecer Gaitán — en la ciudad de Bogotá el 20 de julio de 1940, en un espectáculo que, de acuerdo con lo anunciado, combinaba la proyección

\footnotetext{
${ }^{190}$ Roberto Ornelas, "Radio y cotidianidad en México (1900-1930)", en Historia de la vida cotidiana en México, tomo IV, vol. 1 (México: El Colegio de México-FCE), 142-143.

${ }^{191}$ Velázquez, "La radiodifusión mexicana: encuentro con su pasado (1923-1945)", 304.

192 Marco Palacios, Entre la legitimidad y la violencia. Colombia 1875-1994. Segunda edición corregida y aumentada (Bogotá: Grupo Editorial Norma, 2003), 149.

${ }^{193}$ Hernando Téllez, Cincuenta años de radiodifusión en Colombia (Bogotá: Editorial Bedout S.A, 1974), 39.

194 Téllez, Cincuenta años..., 44-45.
} 
cinematográfica y la interpretación de canciones en vivo de Agustín Lara y del repertorio popular mexicano. Según la prensa bogotana, a este concierto asistió el presidente Eduardo Santos acompañado de su esposa y de algunos miembros del cuerpo diplomático mexicano acreditado en el país, en un acto que generó buenos comentarios por parte de la audiencia ${ }^{195}$.

Otro acontecimiento que vino a dinamizar los canales de comunicación con el continente fue la apertura de los servicios de radiotelegrafía con los que el Gobierno colombiano buscaba optimizar sus sistemas de comunicación con otros Gobiernos. En medio del conflicto bélico europeo, la inauguración del servicio radiotelegráfico entre el Gobierno de México y el de Colombia fue visto como un importante paso para dar conexión a los dos países y buscar economizar costos en lo relativo al intercambio de información. Esta búsqueda de comunicación directa se sumaba a la ya establecida con los Estados Unidos, Brasil, Panamá y Centro América. En torno a este adelanto se pronunciaban de manera amable Luís Buenahora, para la época ministro de comunicaciones en Colombia, y el general Maximino Ávila Camacho, quien en México ejercía como secretario de comunicaciones y obras públicas ${ }^{196}$.

Igualmente, la inauguración de la Radiodifusora Nacional —estación de radio perteneciente al Gobierno Nacional - fue uno de los acontecimientos que vino a dinamizar la radio pública en Colombia. Su apertura en 1940 fue elogiada como un importante acontecimiento para conectar a las distintas regiones del país. Igualmente, los propósitos pedagógicos y educativos de la radio estatal fueron señalados como elementos claves para fortalecer la comunicación cotidiana entre el Gobierno y los ciudadanos, más allá de la propaganda y de los intereses políticos presentes en la vida pública ${ }^{197}$. Para algunos columnistas de la época como el ensayista Baldomero Sanín Cano, la apertura de la Radiodifusora Nacional además de ser un signo de progreso, representaba la oportunidad para proyectar ante las demás naciones aspectos de la cultura y de la inteligencia colombiana, en un contexto de necesaria cercanía con las expresiones artísticas que difundían otros países latinoamericanos ${ }^{198}$. Dado el contexto de la época y el momento bélico vivido en el entorno europeo durante la primera mitad de la década del cuarenta, la radio fue para México y Colombia un importante espacio de interconexión, comunicación y proyección internacional, en tanto que fue visto como un espacio clave para generar unidad continental y crear cercanías entre las repúblicas americanas, en aras de conseguir los propósitos comunicativos y de unidad informativa que el periódico no había podido conseguir en el continente ${ }^{199}$.

\section{Conclusiones}

Las políticas educativas y las nuevas lecturas en torno a la cultura popular se convirtieron en un proceso vinculante para ambas naciones durante los años treinta y cuarenta; en medio de planes y pautas de reorganización curricular que dieron cabida al realce del folclor nacional y a la promoción de valores que resignificaban y creaban nuevas conciencias en torno al nacionalismo y a la pertenencia regional. La cultura entendida a partir de la multiplicidad de expresiones y manifestaciones que definen los rasgos de una sociedad en particular fue un espacio vinculante para ambas naciones, bajo la óptica de sus

\footnotetext{
${ }^{195}$ El Espectador. Julio 21 de 1940. p. 5.

${ }^{196}$ El Tiempo, 21 de marzo de 1942, 15.

${ }^{197}$ El Tiempo, 2 de febrero de 1940, 4.

${ }^{198}$ El Tiempo, 5 de febrero de 1940, 4.

${ }^{199}$ El Tiempo, 5 de febrero de 1940, 4.
} 
intercambios y procesos de interacción, por vías como el cine, la música y la actividad académica adelantada en universidades mexicanas y colombianas.

El nacionalismo mexicano y el discurso liberal que en Colombia identificaba a los gobiernos que ejercieron el poder entre 1930 y 1946 fueron el escenario de importantes procesos de reforma y transformación, en los que campos como la cultura, las relaciones con otros estados y la participación política de nuevos sectores de la sociedad marcaron un punto de encuentro en ambas realidades. La propaganda cultural proyectó sobre Colombia la idea de un México matizado por las imágenes de su folclor, de sus reformas y del realce dado a las expresiones populares, al indigenismo y a las artes, cuyos contenidos narraban vivencias de sectores otrora relegados del universo creativo. El muralismo mexicano, el cine de charros cantores - que en México marcó toda una época de apogeo para la producción nacional—y el repertorio musical de la posrevolución fueron expresiones conocidas en Colombia, de la mano de publicistas, intercambios académicos y canales de distribución internacional cercanos con la industria del entretenimiento. La cultura fue durante este periodo uno de los elementos de enlace de la relación bilateral capaz de ir más allá del plano de la oficialidad y de la esfera institucional, como una especie de correa de trasmisión ligada a un proyecto político tendiente a promover una imagen de lo mexicano en el espectro latinoamericano.

Expresiones como el muralismo, el cine y la música tradicional mexicana lograron ingresar en los ámbitos de consumo cultural de muchas ciudades colombianas, a través de espacios de difusión diversos, entre los que se cuenta el intercambio académico, el cine y la radio. A su modo y en una proporción muy pequeña el arte público colombiano tenía un referente inmediato en la experiencia de los muralistas mexicanos de mayor renombre durante la primera mitad del siglo XX, cuya escuela otorgó interesantes elementos de formación en la carrera artística de algunos artistas nacionales. La promoción que la radio colombiana daba al repertorio musical mexicano y la difusión de canciones revestidas de elementos nacionalistas y de exaltación de un México posrural entraron en estas dinámicas de consumo cultural, junto a ritmos procedentes del ámbito caribeño y de tangos representativos del cancionero argentino. 


\section{Referencias}

\section{Fuentes primarias}

AGNC-FCOI. Archivo General de la Nación Colombia. Fondo Cancillerías. Organismos Internacionales. Legación de Colombia en México.

AGE-SREM. Archivo Genaro Estrada. Secretaria de Relaciones Exteriores México.

Periódico El Espectador 1930-1950. Hemeroteca de la Biblioteca Luis Ángel Arango. Bogotá-Colombia.

Periódico El Tiempo 1930-1950. Hemeroteca de la Biblioteca Luis Ángel Arango. BogotáColombia.

\section{Fuentes secundarias}

Alsina, Miquel Rodrigo. "Elementos para una comunicación intercultural". Revsia CIBOD $d$ 'Afers Internacionals n. ${ }^{\circ}$ 36, 1997.

Bolívar, Rosendo. "El lombardismo y la Confederación de Trabajadores de América Latina". Revista Mexicana de Ciencias Políticas y Sociales 41, n.o 163 (1996): 189-220.

Braunw, Herbert. Mataron a Gaitán. Vida pública y violencia urbana en Colombia. Editorial Aguilar, 1985.

Chica, Ricardo. "La apropiación social del cine mexicano de la época de oro en Cartagena de Indias, Colombia 1936-1957”. Ponencia leída en el II Encuentro de Estudios Históricos Comparados México-Colombia, UPTC, Tunja, agosto de 2014.

De los Reyes, Aurelio. Medio siglo de cine mexicano. México: Editorial Trillas, 1987. . Escritores en la diplomacia mexicana. SRE. México, 1998.

Flórez, Miguel Ángel. Mario Moreno Cantinflas. El filósofo de la risa. Bogotá: Editorial Panamericana, 2005.

García, Néstor, ed. "Políticas culturales y crisis de desarrollo: un balance latinoamericano". En Políticas Culturales en América Latina, 13-61. México: Editorial Grijalbo, 1987.

García, Emilio. El cine mexicano. México: Ediciones Era, 1963.

González, Luis. Los artífices del cardenismo. México: El Colegio de México, 1979.

Guerrero, Javier. El proceso político de las derechas en Colombia y los imaginarios sobre las guerras internacionales. 1930-1945. Tunja: UPTC, 2014.

Guilly, Adolfo. El cardenismo. Una utopía mexicana. México: Ediciones Era, 1994. 
Knight, Alan. "Racismo, revolución e indigenismo: México, 1910-1940". Repensar la Revolución Mexicana II. El Colegio de México (2004): 49-109.

Lerner, Bertha y Susana Ralsky. El poder de los presidentes. Alcances y perspectivas. 19101973. México: IMEP, 1976.

Mac Gregor, Javier. "El nuevo presidencialismo, corporaciones y partidos políticos". En El cardenismo, 1932-1940, coordinado por Samuel León y Gonzales, 324-369. México: FCE, 2011.

Medina, Luis. Historia de la Revolución Mexicana. Del cardenismo al avilacamachismo. Tomo 18. México: El Colegio de México, 1978.

Moreno, Yolanda. Historia de la música popular mexicana. México, D.F.: Alianza Editorial Mexicana, 1979.

Niblo, Stephen. México en los cuarenta. Modernidad y corrupción. México, Editorial Océano, 2008.

Ornelas, Roberto. "Radio y cotidianidad en México (1900-1930)". En Historia de la vida cotidiana en México, tomo IV, vol. 1, 127-169. México: El Colegio de México-FCE.

Palacios, Marco. Entre la legitimidad y la violencia. Colombia 1875-1994. Segunda edición corregida y aumentada. Bogotá: Grupo Editorial Norma, 2003.

Pérez, Ricardo. Estampas de nacionalismo popular mexicano. Ensayos sobre cultura popular y nacionalismo. México, D.F: CIESAS, 1994.

. Cotidianidades, imaginarios y contextos: ensayos de historia y cultura en México. 1850-1950. México: CIESAS, 2008.

Picón-Salas, Mariano. "Lo hispanoamericano desde los Estados Unidos". Cuadernos Americanos 15, mayo-junio (1944): 57-66.

Rico, Angie. Bucaramanga en la penumbra. La exhibición cinematográfica 1897-1950. Bucaramanga: Universidad Industrial de Santander, 2013.

Silva, Renán. República Liberal Intelectuales y Cultura Popular. Medellín: La Carreta, 2005.

Spenser, Daniela. "La cimentación de la Confederación de Trabajadores de México". Tzintzun. Revista de Estudios Históricos, n. ${ }^{\circ}$ 60, julio-diciembre (2014): 248-279.

Téllez, Hernando. Cincuenta años de radiodifusión en Colombia. Bogotá: Editorial Bedout S.A, 1974.

Urfalino, Philippe. "La historia de la política cultural". En Para una historia cultural, JeanPierre Rioux y Jean François Sirinelli, 327-340. México: Editorial Taurus, 1997. 
Velázquez, Rosalía. "La radiodifusión mexicana: encuentro con su pasado (1923-1945)". En Miradas sobre la nación liberal: 1848-1948. Proyectos, debates y desafios. Formar e informar: la diversidad cultura, libro 2, Josefina Mac Gregor, 275-313. México: Universidad Nacional Autónoma de México, 2010.

Wiesner, Helena. Murales capitolinos de Ignacio Gómez Jaramillo y Santiago Martínez Delgado. (Bogotá, 1938-1948). Bogotá: Academia Colombiana de Historia, 2014.

Yankelevich, Pablo. La revolución mexicana en América Latina. Intereses políticos e itinerarios intelectuales. México: Instituto Mora, 2003. 